\begin{tabular}{|c|c|}
\hline Title: & $\begin{array}{l}\text { Analytical model of a six-phase PMSM for the simulation of stator winding faults on turn } \\
\text { level }\end{array}$ \\
\hline Authors: & Simon Foitzik, Martin Doppelbauer \\
\hline Institute: & $\begin{array}{l}\text { Karlsruhe Institute of Technology (KIT) } \\
\text { Institute of Electrical Engineering (ETI) }\end{array}$ \\
\hline Type: & Conference Proceedings \\
\hline Published at: & $\begin{array}{l}\text { 11th IEEE International Electric Machines and Drives Conference, IEMDC 2019; San } \\
\text { Diego; United States; } 12 \text { May } 2019 \text { through } 15 \text { May } 2019 \\
\text { Publisher: IEEE } \\
\text { Year: } 2019 \\
\text { ISBN: } 978-1-5386-9349-0 \\
\text { Pages: } 185-191\end{array}$ \\
\hline Hyperlinks: & https://ieeexplore.ieee.org/document/8785351 \\
\hline
\end{tabular}

(c) 2019 IEEE. Personal use of this material is permitted. Permission from IEEE must be obtained for all other uses, in any current or future media, including reprinting/republishing this material for advertising or promotional purposes, creating new collective works, for resale or redistribution to servers or lists, or reuse of any copyrighted component of this work in other works. 


\section{Analytical Model of a Six-Phase PMSM for the Simulation of Stator Winding Faults on Turn Level}

\author{
Simon Foitzik \\ Institute of Electrical Engineering (ETI) \\ Karlsruhe Institute of Technology (KIT) \\ Karlsruhe, Germany \\ simon.foitzik@kit.edu
}

\author{
Martin Doppelbauer \\ Institute of Electrical Engineering (ETI) \\ Karlsruhe Institute of Technology (KIT) \\ Karlsruhe, Germany \\ martin.doppelbauer@kit.edu
}

\begin{abstract}
The major limitation of the lifetime and reliability of electrical machines are stator winding faults. Inter-turn faults are for that matter often the origin of more severe faults, which can lead to complete system failures. Particularly, threephase permanent magnet synchronous machines (PMSMs) have significant drawbacks in terms of fault tolerant operation. In comparison, six-phase PMSMs are more complex to analyze and to operate, but for this reason, also offer greater possibilities for the control scheme during fault. This paper presents the first analytical machine model to investigate the behavior of six-phase PMSMs with stator winding faults on turn level. In order to keep the model compact, the levels of abstraction vary within the stator winding circuit. The machine model is acausally implemented, which allows the simulation with current sources and current controlled voltage sources. The simulation results of the presented model are compared with the simulation results of an equivalent finite element analysis model. The average torque differs between the two models in case of an inter-turn fault at nominal load operation by $0.3 \%$, the amplitude of the fault current differs by $3.3 \%$ and the frequency spectra of the voltages show equal characteristics, while the computation time is 200 times faster with the analytical model. We use the developed model for the analysis of the machine behavior under stator winding faults relevant in practice. With the machine analysis's outcome, we are able to develop a more sophisticated fault management system, which enhances fault tolerant operation in comparison with three-phase PMSMs.
\end{abstract}

Index Terms-stator winding faults, six-phase, inter-turn faults, PMSM, acausal implementation, analytical model

\section{INTRODUCTION}

Fault tolerant propulsion systems are necessary for upcoming topics in safety critical applications, like all-electric aircraft [1]. These systems can still operate under faulty conditions with reduced or even full power. A fault management system (FMS) is required to enable fault tolerant operation [2]. An inter-turn fault is most commonly the initial fault in the stator winding of an electrical machine [3]. The FMS must be able to detect these minor faults in an early stage and must adopt the control strategy in order to maintain safe operation [4]. Otherwise, the inter-turn fault propagates to more serious faults, which can have a severe impact on safety critical applications. Therefore, the FMS requires detailed knowledge of the electrical machine under healthy and faulty conditions. Multiphase machines inherently feature an increased fault tolerance compared with conventional three-phase systems
[5]. For that matter, six-phase systems are practical to use because they can be built with two three-phase systems. There exist several methods of analytical modeling of interturn faults for three-phase permanent magnet synchronous machines (PMSMs) with surface mounted magnets [6], [7]. We propose in [8] an analytical model for an acausal simulation of stator winding faults of PMSMs with surface mounted or buried magnets. There is only one approach for six-phase interturn fault modeling for induction machines [9] and none fore six-phase PMSMs. This paper presents the first approach to simulate user-defined stator winding faults on turn level of PMSMs with rotor position dependent inductance.

\section{Modeling}

There are several descriptions in literature of multiphase machines. Electrical machines can be classified by their number of phases and their phase belt angle $\beta$. In this paper, we focus on six-phase machines with a phase belt angle of $\beta=30$ electrical degrees, which is called "semi 12-phase" in [10]. The same type of winding is called "duplex" winding in [11] since it can be built by a duplicated three-phase machine. One set of three-phase winding with a phase belt angle of $\beta=60$ electrical degrees is divided into two sets of three-phase windings with a phase belt angle of $\beta=30$ electrical degrees each. The two sets of windings are displaced by an angle of 30 electrical degrees. Fig. 1 shows the phase arrangement of the analyzed six-phase machine. Therein $\gamma_{1}$ denotes the rotor angle in reference to phase $\mathrm{Ph} 1$ and $\gamma_{2}$ denotes the rotor angle in reference to phase $\mathrm{Ph} 4$. Phases $\mathrm{Ph} 1, \mathrm{Ph} 2$, and $\mathrm{Ph} 3$ are part of the first three-phase system and phases $\mathrm{Ph} 4, \mathrm{Ph} 5$, and $\mathrm{Ph} 6$ of the second three-phase system. Fig. 2 shows the cross section of the analyzed six-phase machine. The color of the slots matches the corresponding three-phase system of Fig.1.

\section{A. Assumptions}

The following assumptions are used to model the machine. The stator winding consists of six distributed, symmetric and full-pitched phases. The six phases are divided into two star-connected three-phase systems, which are shifted by 30 electrical degrees. The star points of the two three-phase systems are not connected to each other and are not attached to the converter. The number of pole pairs is two, the number 


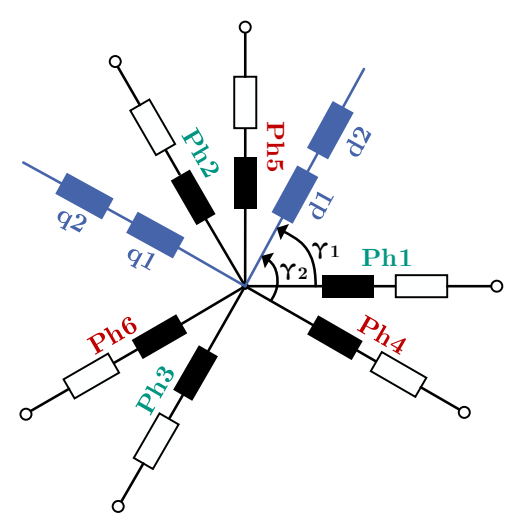

Fig. 1. Phase arrangement of the stator winding.

of slots per pole per phase is one, the number of parallel paths is one and the number of turns per coil is 23 . The permeability of the iron approaches infinity, the magnetic circuit is linear and there exists no magnetic coupling among different pole pairs. We only regard the fundamental wave in the air gap and we neglect the stator winding end effects. Furthermore, we neglect friction loss, iron loss, dielectric currents, skin effects and proximity effects. We assume that the inductances and the flux linkage are given in the dq-reference frame. These values can be obtained by either measurement, theoretical calculation, finite element analysis (FEA) simulation or the data sheet of the machine.

\section{B. Healthy Machine}

The stationary voltage equation of the duplex machine is given in the dq-reference frame by [11]:

$$
\begin{aligned}
& v_{\mathrm{d} 1}=R_{\mathrm{Ph}} \cdot i_{\mathrm{d} 1}-\omega\left(L_{\mathrm{q} 1} \cdot i_{\mathrm{q} 1}+M_{\mathrm{q} 1 \mathrm{q} 2} \cdot i_{\mathrm{q} 2}\right) \\
& v_{\mathrm{q} 1}=R_{\mathrm{Ph}} \cdot i_{\mathrm{q} 1}+\omega\left(L_{\mathrm{d} 1} \cdot i_{\mathrm{d} 1}+M_{\mathrm{d} 1 \mathrm{~d} 2} \cdot i_{\mathrm{d} 2}+\Psi_{\mathrm{PM} 1}\right) \\
& v_{\mathrm{d} 2}=R_{\mathrm{Ph}} \cdot i_{\mathrm{d} 2}-\omega\left(L_{\mathrm{q} 2} \cdot i_{\mathrm{q} 2}+M_{\mathrm{q} 2 \mathrm{q} 1} \cdot i_{\mathrm{q} 1}\right) \\
& v_{\mathrm{q} 2}=R_{\mathrm{Ph}} \cdot i_{\mathrm{q} 2}+\omega\left(L_{\mathrm{d} 2} \cdot i_{\mathrm{d} 2}+M_{\mathrm{d} 2 \mathrm{~d} 1} \cdot i_{\mathrm{d} 1}+\Psi_{\mathrm{PM} 2}\right)
\end{aligned}
$$

Therein $v_{\mathrm{d} 1}$ and $v_{\mathrm{q} 1}$ denote the voltage in d-and q-axis of the first and $v_{\mathrm{d} 2}$ and $v_{\mathrm{q} 2}$ of the second three-phase system. $L_{\mathrm{d} 1}$ and $L_{\mathrm{q} 1}$ denote the inductances in d- and q-axis of the first and $L_{\mathrm{d} 2}$ and $L_{\mathrm{q} 2}$ of the second three-phase system. $M_{\mathrm{d} 1 \mathrm{~d} 2}, M_{\mathrm{d} 2 \mathrm{~d} 1}$, $M_{\mathrm{q} 1 \mathrm{q} 2}$ and $M_{\mathrm{q} 2 \mathrm{q} 1}$ denote the mutual inductances among the two systems. The permanent magnet flux linkage of the rotor is denoted by $\Psi_{\mathrm{PM} 1}$ and $\Psi_{\mathrm{PM} 2}$ for the first and second threephase system, respectively. The ohmic phase resistance is denoted by $R_{\mathrm{Ph}}$ and the angular velocity is denoted by $\omega$. The voltage equations (1)-(4) can be summarized to a vectorial representation:

$$
\boldsymbol{v}_{\mathrm{dq}}=\boldsymbol{R}_{\mathrm{Ph}} \cdot \boldsymbol{i}_{\mathrm{dq}}+\omega\left(\boldsymbol{L}_{\mathrm{dq}} \cdot \boldsymbol{i}_{\mathrm{dq}}+\boldsymbol{\Psi}_{\mathrm{PM}, \mathrm{dq}}\right)
$$

Therein $\boldsymbol{v}_{\mathrm{dq}}(4 \times 1)$ denotes the vector of the dq-voltages, $\boldsymbol{R}_{\mathrm{Ph}}(4 \times 4)$ denotes the matrix of the ohmic phase resistances, $\boldsymbol{i}_{\mathrm{dq}}(4 \times 1)$ denotes the vector of the dq-currents, $\boldsymbol{L}_{\mathrm{dq}}(4 \times 4)$ denotes the dq-inductances and $\boldsymbol{\Psi}_{\mathrm{PM}, \mathrm{dq}}(4 \times 1)$ denotes the dqpermanent magnet flux linkages. The transformation matrices

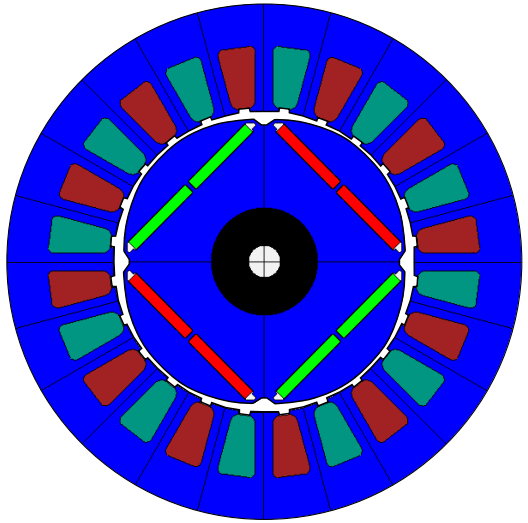

Fig. 2. Cross section of the analyzed PMSM.

$\boldsymbol{T}_{1}$ and $\boldsymbol{T}_{2}$ are used to transform the voltage equations of the rotating reference frame into the stationary reference frame. The general transformation matrix $\boldsymbol{T}$ is given by:

$$
\boldsymbol{T}=\frac{2}{3}\left(\begin{array}{ccc}
\cos (\gamma) & \cos (\gamma-2 \pi / 3) & \cos (\gamma+2 \pi / 3) \\
-\sin (\gamma) & -\sin (\gamma-2 \pi / 3) & -\sin (\gamma+2 \pi / 3)
\end{array}\right)
$$

The matrices $\boldsymbol{T}_{1}$ and $\boldsymbol{T}_{2}$ use $\gamma_{1}$ and $\gamma_{2}$ as transformation angle. The phase inductance matrix $\boldsymbol{L}_{\mathrm{Ph}}(6 \times 6)$ is calculated by:

$$
\boldsymbol{L}_{\mathrm{Ph}}=\left(\begin{array}{cc}
\boldsymbol{T}_{1} \boldsymbol{L}_{\mathrm{dq}, 1} \boldsymbol{T}_{1}^{-1} & \boldsymbol{T}_{1} \boldsymbol{M}_{12} \boldsymbol{T}_{2}^{-1} \\
\boldsymbol{T}_{2} \boldsymbol{M}_{21} \boldsymbol{T}_{1}^{-1} & \boldsymbol{T}_{2} \boldsymbol{L}_{\mathrm{dq}, 2} \boldsymbol{T}_{2}^{-1}
\end{array}\right)
$$

In this equation the indexes 1 and 2 refer to the first and second three-phase system, respectively. The voltage equation of the synchronous machine in the stationary reference frame is given by:

$$
\boldsymbol{v}_{\mathrm{Ph}}=\boldsymbol{R}_{\mathrm{Ph}} \cdot \boldsymbol{i}_{\mathrm{Ph}}+\frac{\mathrm{d}}{\mathrm{d} t}\left(\boldsymbol{L}_{\mathrm{Ph}} \cdot \boldsymbol{i}_{\mathrm{Ph}}+\boldsymbol{\Psi}_{\mathrm{PM}, \mathrm{Ph}}\right)
$$

Therein $\boldsymbol{v}_{\mathrm{Ph}}(6 \times 1)$ denotes the phase voltage vector, $\boldsymbol{i}_{\mathrm{Ph}}$ $(6 \times 1)$ denotes the phase current vector and $\boldsymbol{\Psi}_{\mathrm{PM}, \mathrm{Ph}}(6 \times 1)$ denotes the vector of the phase permanent magnet flux linkage. These values are calculated by using the transformation matrices $\boldsymbol{T}_{1}$ and $\boldsymbol{T}_{2}$, similarly to (7).

\section{Faulty Machine}

Inter-turn faults most likely occur at the first turns of a coil, because of the increased voltage stress in adjustablespeed drive systems [12]. We model the PMSM on turn level in the faulty machine part, to enable the simulation of interturn faults. The healthy machine part can be reduced to a more abstract level in order to have a compact model. Thus, the machine model contains two levels of abstraction. For the first level, the phase inductance is separated into the phase inductance per pole, P1 and P2. For the second level, the phase inductance of pole P1 is further separated into the faulty parts F1 and F2. The sum of the turns from part F1 and F2 must equal the original number of turns from one pole. The resulting model of the stator winding circuit is shown in Fig. 3. The 


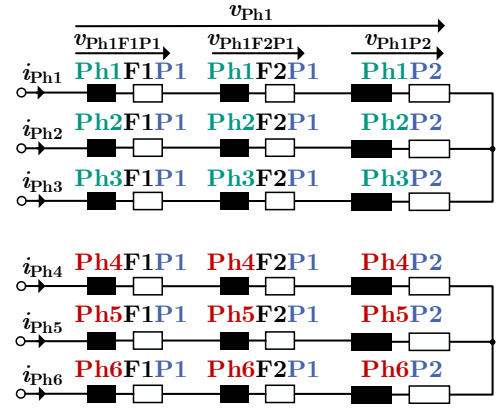

Fig. 3. Implemented electric circuit of the machine model.

voltage equation for the stator winding of the fault model is given by:

$$
\boldsymbol{v}_{\mathrm{FM}}=\boldsymbol{R}_{\mathrm{FM}} \cdot \boldsymbol{i}_{\mathrm{FM}}+\frac{\mathrm{d}}{\mathrm{d} t}\left(\boldsymbol{L}_{\mathrm{FM}} \cdot \boldsymbol{i}_{\mathrm{FM}}+\boldsymbol{\Psi}_{\mathrm{PM}, \mathrm{FM}}\right)
$$

Therein the vector $\boldsymbol{v}_{\mathrm{FM}}(18 \times 1)$ contains the voltage of each component, the matrix $\boldsymbol{R}_{\mathrm{FM}}(18 \times 18)$ contains the ohmic resistance of each component, the vector $\boldsymbol{i}_{\mathrm{FM}}(18 \times 1)$ contains the current through each component, the matrix $\boldsymbol{L}_{\mathrm{FM}}(18 \times 18)$ contains the inductive coupling among all components and the vector $\boldsymbol{\Psi}_{\mathrm{PM}, \mathrm{FM}}(18 \times 1)$ contains the permanent magnet flux linkage of each component. We use the phase model to calculate the resistance matrix, the inductance matrix and the permanent magnet flux linkage vector of the fault model. For the derivation, we use the voltage equation of each phase. As shown in Fig. 3, the phase voltage equation for phase $\mathrm{Ph} i$, $i \in\{1,2, \ldots, 6\}$ is given by:

$$
\begin{aligned}
v_{\mathrm{Ph} i} & =R_{\mathrm{Ph}} \cdot i_{\mathrm{Ph} i}+\frac{\mathrm{d}}{\mathrm{d} t} \Psi_{\mathrm{Ph} i} \\
& =v_{\mathrm{Ph} i \mathrm{~F} 1 \mathrm{P} 1}+v_{\mathrm{Ph} i \mathrm{~F} 2 \mathrm{P} 1}+v_{\mathrm{Ph} i \mathrm{P} 2}
\end{aligned}
$$

Due to this information, we can calculate $\boldsymbol{R}_{\mathrm{FM}}, \boldsymbol{L}_{\mathrm{FM}}$ and $\boldsymbol{\Psi}_{\mathrm{PM}, \mathrm{FM}}$ using $\boldsymbol{R}_{\mathrm{Ph}}, \boldsymbol{L}_{\mathrm{Ph}}$ and $\boldsymbol{\Psi}_{\mathrm{PM}, \mathrm{Ph}}$, respectively. The individual values are calculated by:

$$
\begin{gathered}
R_{\mathrm{Ph} i(\mathrm{~F} j) \mathrm{P} k}=R_{\mathrm{Ph} i} \frac{w_{\mathrm{Ph} i(\mathrm{~F} j) \mathrm{P} k}}{w_{\mathrm{Ph} i}} \\
\Psi_{\mathrm{PM}, \mathrm{Ph} i(\mathrm{~F} j) \mathrm{P} k}=\Psi_{\mathrm{PM}, \mathrm{Ph} i} \frac{w_{\mathrm{Ph} i(\mathrm{~F} j) \mathrm{P} k}}{w_{\mathrm{Ph} i}} \\
L_{\mathrm{Ph} i(\mathrm{~F} j) \mathrm{P} k, \mathrm{Ph} m(\mathrm{~F} n) \mathrm{P} o}=L_{\mathrm{Ph} i, \mathrm{Ph} m} \frac{w_{\mathrm{Ph} i(\mathrm{~F} j) \mathrm{P} k} w_{\mathrm{Ph} m(\mathrm{~F} n) \mathrm{P} o}}{w_{\mathrm{Ph} i} w_{\mathrm{Ph} m}}
\end{gathered}
$$

Therein every component can be addressed individually with $i, m \in\{1,2, \ldots, 6\}$ and $j, k, n, o \in\{1,2\}$. The power equation is derived by multiplying the voltage equation (9) with the transposed current vector $\boldsymbol{i}_{\mathrm{FM}}^{\mathrm{T}}$ :

$$
\begin{aligned}
\boldsymbol{i}_{\mathrm{FM}}^{\mathrm{T}} \cdot \boldsymbol{v}_{\mathrm{FM}} & =\boldsymbol{i}_{\mathrm{FM}}^{\mathrm{T}} \cdot \boldsymbol{R}_{\mathrm{FM}} \cdot \boldsymbol{i}_{\mathrm{FM}}+\boldsymbol{i}_{\mathrm{FM}}^{\mathrm{T}} \cdot \frac{\mathrm{d}}{\mathrm{d} t} \boldsymbol{\Psi}_{\mathrm{FM}} \\
P_{\mathrm{el}} & =P_{\mathrm{loss}}+\frac{\mathrm{d} W_{\mathrm{mag}}}{\mathrm{d} t}+P_{\mathrm{mech}}
\end{aligned}
$$

The electric power $P_{\mathrm{el}}$ separates into the power loss $P_{\text {loss }}$, the derivative of the stored magnetic energy $\frac{\mathrm{d} W_{\operatorname{mag}}}{\mathrm{d} t}$ and the inner mechanical power $P_{\text {mech }}$. In a machine with a symmetric matrix of the phase inductance, the average change of stored magnetic energy is zero over time and can be neglected [11]. Thus, the equation for the electromagnetic torque $T_{\mathrm{el}}$ can be derived from $P_{\text {mech }}$, wherein $\Omega$ denotes the mechanical angular velocity of the rotor:

$$
T_{\mathrm{el}}=\frac{1}{\Omega} \cdot P_{\mathrm{mech}}=\frac{1}{\Omega} \cdot \boldsymbol{i}_{\mathrm{FM}}^{\mathrm{T}} \cdot \frac{\mathrm{d}}{\mathrm{d} t} \boldsymbol{\Psi}_{\mathrm{FM}}
$$

\section{IMPLEMENTATION}

The implementation of machine models can be divided into causal and acausal approaches [13]. Causally implemented machine models offer reduced simulation time compared with acausally implemented models. The disadvantage of a causal implementation is the predefined information flow. This means that the specification of the input and output ports of the machine model cannot be changed once the model is implemented. Causally implemented machine models mainly use a voltage source as input [14], [15]. This allows the simulation of propulsion systems with current controlled voltage source inverters (VSIs). For the analysis of the machine behavior under faulty conditions, we first simulate the machine model without interference of a current controller. Therefore, we use current sources to set a desired torque according to (17). In a second step, we will analyze the machine behavior under faulty conditions, with the interference of a current controlled VSI. This means we need an acausally implemented machine model with a nondirectional information flow. With this approach, we can either use a current source or a voltage source for the analysis of the machine. We used the MATLAB ${ }^{\circledR}$ Simscape $^{\mathrm{TM}}$ environment to implement the analytical model of the sixphase PMSM. To ensure the nondirectional information flow, the electrical domain is implemented with differential equations. Each component of the stator winding is modeled by a customized component and the connection of all components forms the stator winding of Fig. 3. The implementation of such a component, which includes the corresponding voltage equation of (9), is shown in Fig. 4. By adding short circuit paths to the stator winding, we can simulate inter-turn faults, phase-to-phase faults or phase-to-ground faults. Furthermore, we can simulate open circuit faults by adding an open circuit to the stator winding. Fig. 5 shows an added short circuit path in phase $\mathrm{Ph} 1$ for the simulation of an inter-turn fault with variable number of turns $w_{\mathrm{Ph} 1 \mathrm{~F} 1 \mathrm{P} 1}$.

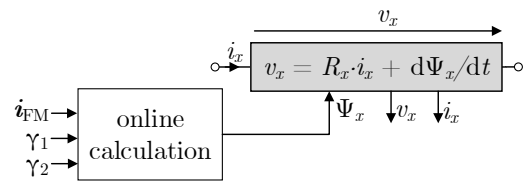

Fig. 4. Implemented customized component of an inductance. 


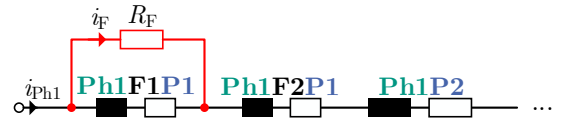

Fig. 5. Implemented inter-turn fault by adding a short circuit path.

\section{Finite Element Analysis}

We use a 2D FEA simulation in this paper to compare the simulation results of the analytical model. We perform the FEA simulation with the software Flux ${ }^{\mathrm{TM}}$ from Altair $^{\circledR}$. The cross section of the analyzed six-phase PMSM with buried magnets is shown in Fig. 2. The electric circuits of both models are equal. In contrast to the analytical model, the FEA model considers the nonlinear magnetic circuit of the machine. We also use the FEA model to determine the flux linkages $\Psi_{\mathrm{PM} 1}$ and $\Psi_{\mathrm{PM} 2}$, the self-inductances $L_{\mathrm{d} 1}, L_{\mathrm{q} 1}, L_{\mathrm{d} 2}$ and $L_{\mathrm{q} 2}$ and the mutual inductances $M_{\mathrm{d} 1 \mathrm{~d} 2}, M_{\mathrm{d} 2 \mathrm{~d} 1}, M_{\mathrm{q} 1 \mathrm{q} 2}$ and $M_{\mathrm{q} 2 \mathrm{q} 1}$ of the healthy machine by linearization at the nominal operating point. The machine parameters are summarized in Table I. The self-inductances $L_{\mathrm{d} 1}$ and $L_{\mathrm{d} 2}$ and the mutual inductances $M_{\mathrm{d} 1 \mathrm{~d} 2}$ and $M_{\mathrm{d} 2 \mathrm{~d} 1}$ are equal because there is no displacement angle among the $\mathrm{d} 1$ - and $\mathrm{d} 2$-axes according to Fig. 1. For the same reason, the self-inductances and the mutual inductances of the q1- and q2-axes are equal. There is no magnetic coupling among the $\mathrm{d}$ - and q-axes, because the displacement angle is 90 electrical degrees.

\section{REsults}

The simulation results of the analytical and FEA model are presented and compared for four different operating scenarios, as shown in Table II. In case of no load operation, the phase currents are equal to zero. The nominal load operation is defined by the Maximum Torque per Ampere (MTPA) approach. The nominal MTPA point for the presented PMSM is defined by the current amplitude $\left|i_{\mathrm{dq}}\right|=10 \mathrm{~A}$ and the current angle $\theta=8$ electrical degrees, which equals $i_{\mathrm{q} 1}=i_{\mathrm{q} 2}=9.9 \mathrm{~A}$ and $i_{\mathrm{d} 1}=i_{\mathrm{d} 2}=-1.4 \mathrm{~A}$. The increased speed scenario is used to analyze the impact of an increased induced voltage by the permanent magnets and the impact of an increased electrical frequency. We use the increased load operation to analyze

TABLE I

Machine PARAmeters

\begin{tabular}{lr}
\hline parameters & values \\
\hline self-inductances $L_{\mathrm{d} 1}, L_{\mathrm{d} 2}$ & $0.697 \mathrm{mH}$ \\
self-inductances $L_{\mathrm{q} 1}, L_{\mathrm{q} 2}$ & $2.1 \mathrm{mH}$ \\
mutual inductances $M_{\mathrm{d} 1 \mathrm{~d} 2}, M_{\mathrm{d} 2 \mathrm{~d} 1}$ & $0.697 \mathrm{mH}$ \\
mutual inductances $M_{\mathrm{q} 1 \mathrm{q} 2}, M_{\mathrm{q} 2 \mathrm{q} 1}$ & $2.1 \mathrm{mH}$ \\
permanent magnet flux linkages $\Psi_{\mathrm{PM} 1}, \Psi_{\mathrm{PM} 2}$ & $148 \mathrm{mVs}$ \\
ohmic phase resistance $R_{\mathrm{Ph}}$ & $10 \mathrm{~m} \Omega$ \\
nominal torque $T_{\mathrm{el}}$ & $6.4 \mathrm{Nm}$ \\
\hline
\end{tabular}

TABLE II

SIMULATION SCENARIOS

\begin{tabular}{lccc}
\hline scenario & current amplitude & current angle & speed \\
\hline no load & $0 \mathrm{~A}$ & 0 degrees & $5000 \mathrm{rpm}$ \\
nominal load & $10 \mathrm{~A}$ & 8 degrees & $5000 \mathrm{rpm}$ \\
increased load & $14 \mathrm{~A}$ & 8 degrees & $5000 \mathrm{rpm}$ \\
increased speed & $10 \mathrm{~A}$ & 8 degrees & $7500 \mathrm{rpm}$ \\
\hline
\end{tabular}

the effect of the neglected nonlinear magnetic circuit of the analytical model. The machine parameters are the same for all scenarios. A current source is used for both models to set the different operating scenarios. In the following subsections, the simulation results for an inter-turn fault with two shorted turns $w_{\mathrm{Ph} 1 \mathrm{~F} 1 \mathrm{P} 1}=2$ in phase $\mathrm{Ph} 1$ with a fault resistance $R_{\mathrm{F}}=40 \mathrm{~m} \Omega$ are presented.

\section{A. Voltages}

Fig. 6 shows the simulation results of the voltages $v_{\mathrm{d} 1}, v_{\mathrm{q} 1}$, $v_{\mathrm{d} 2}$ and $v_{\mathrm{q} 2}$ of the FEA model for the operation with increased speed. For this operating scenario, the machine behavior differs the most in comparison to the healthy machine. The effect of the inter-turn fault on the harmonic characteristics of the voltages $v_{\mathrm{d} 1}$ and $v_{\mathrm{q} 1}$ is similar to the effect on the voltages $v_{\mathrm{d} 2}$ and $v_{\mathrm{q} 2}$. Therefore, we use in this paper only the simulation results of the voltages $v_{\mathrm{d} 1}$ and $v_{\mathrm{q} 1}$ to compare both models. The simulation results of the dq-voltages for the first three-phase system are shown in Fig. 7. Due to the inter-turn fault, there are second and fourth harmonics in the voltages. The amplitudes and phase angles of the second harmonics ${ }^{2} v_{\mathrm{q} 1}$ and ${ }^{2} v_{\mathrm{q} 2}$ are the most relevant fault characteristics, because their amplitudes are significantly larger then than the amplitudes of ${ }^{2} v_{\mathrm{d} 1},{ }^{2} v_{\mathrm{d} 2}$ and the amplitudes of the fourth harmonics. Table III summarizes the average voltages $\bar{v}_{\mathrm{q} 1}$ and the amplitudes of the second harmonics ${ }^{2} v_{\mathrm{q} 1}$. The minimum deviation between the FEA and analytical model occurs in case of nominal load operation. In this scenario, the average voltage $\bar{v}_{\mathrm{q} 1}$ of the analytical model differs by $0.1 \%$ in comparison to the FEA Model. The maximum deviation occurs in case of increased load operation. The second harmonic ${ }^{2} v_{\mathrm{q} 1}$ of the analytical model differs, in this case by $7.5 \%$. The average voltage $\bar{v}_{\mathrm{q} 1}$ at nominal load operation is reduced compared

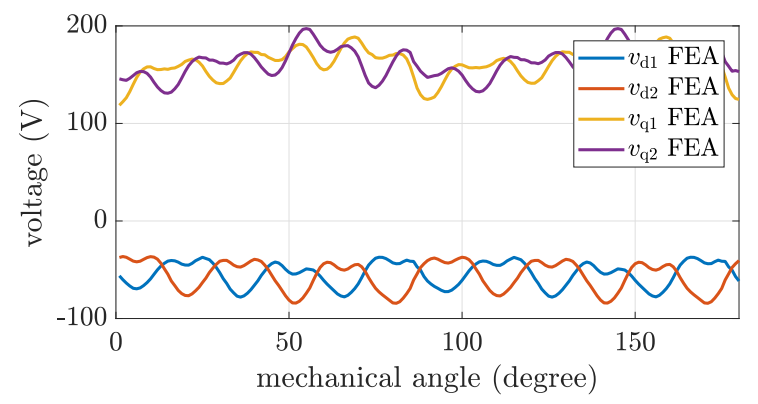

Fig. 6. Operation with increased speed: $\left|i_{\mathrm{dq}}\right|=10 \mathrm{~A}, n=7500 \mathrm{rpm}$ 


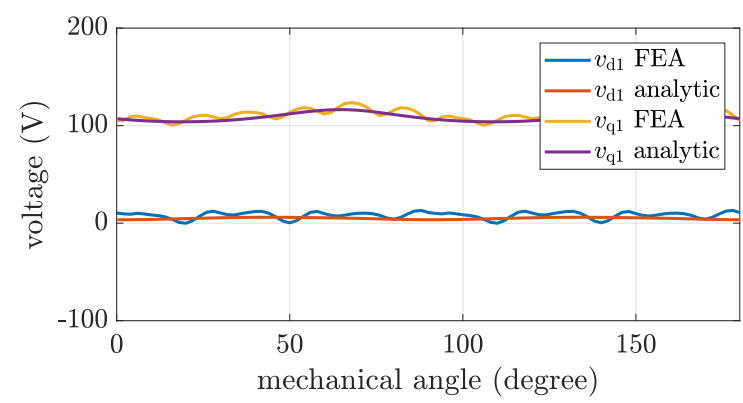

(a) Operation at no load: $\left|i_{\mathrm{dq}}\right|=0 \mathrm{~A}, n=5000 \mathrm{rpm}$

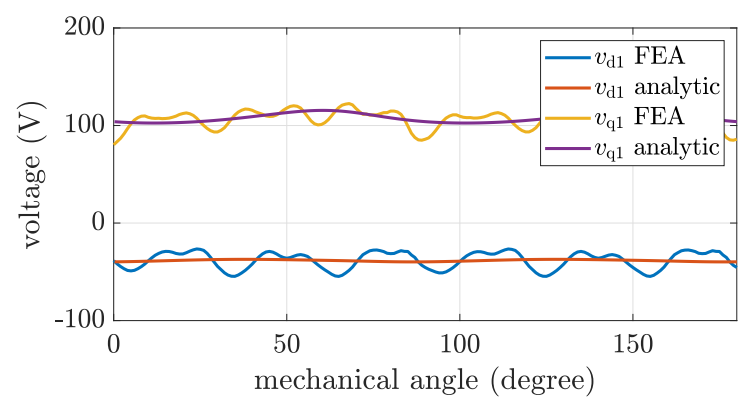

(b) Operation at nominal load: $\left|i_{\mathrm{dq}}\right|=10 \mathrm{~A}, n=5000 \mathrm{rpm}$

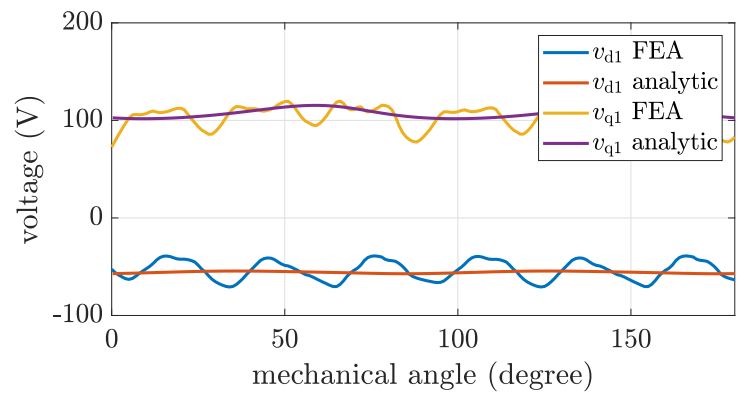

(c) Operation with increased load: $\left|i_{\mathrm{dq}}\right|=14 \mathrm{~A}, n=5000 \mathrm{rpm}$

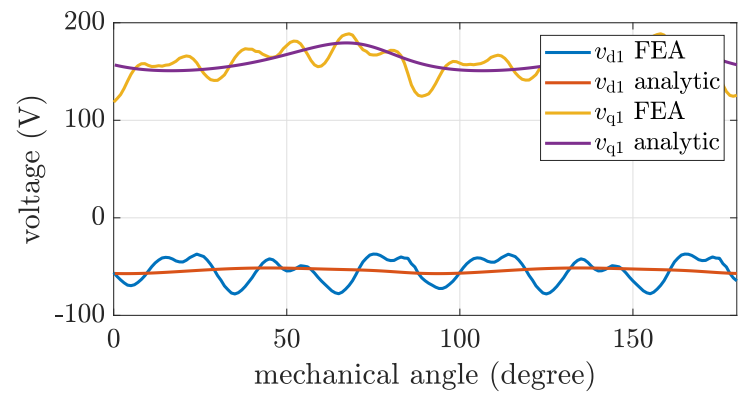

(d) Operation with increased speed: $\left|i_{\mathrm{dq}}\right|=10 \mathrm{~A}, n=7500 \mathrm{rpm}$

Fig. 7. Simulation results of the voltages for the analytical and FEA model with an inter-turn fault in phase Ph1.

to the no load operation because of the negative currents $i_{\mathrm{d} 1}$ and $i_{\mathrm{d} 2}$ according to (2). For the increased load scenario, the average voltage $\bar{v}_{\mathrm{q} 1}$ decreases further. The amplitude of the fundamental component of the phase voltage ${ }^{1} v_{\mathrm{Ph}}$ increases from $110 \mathrm{~V}$ at no load operation, to $114.8 \mathrm{~V}$ at nominal load operation, to $121.3 \mathrm{~V}$ at increased load operation and
TABLE III

COMPARISON OF THE VOLTAGES

\begin{tabular}{lcccc}
\hline & \multicolumn{2}{c}{ FEA } & \multicolumn{2}{c}{ analytic } \\
\hline \multirow{2}{*}{ no load } & $\bar{v}_{\mathrm{q} 1}$ & ${ }^{2} v_{\mathrm{q} 1}$ & $\bar{v}_{\mathrm{q} 1}$ & ${ }^{2} v_{\mathrm{q} 1}$ \\
nominal load & $111.8 \mathrm{~V}$ & $5.9 \mathrm{~V}$ & $109.3 \mathrm{~V}$ & $6.1 \mathrm{~V}$ \\
increased load & $108.3 \mathrm{~V}$ & $6.2 \mathrm{~V}$ & $108.2 \mathrm{~V}$ & $6.4 \mathrm{~V}$ \\
increased speed & $105.4 \mathrm{~V}$ & $6.2 \mathrm{~V}$ & $107.8 \mathrm{~V}$ & $6.7 \mathrm{~V}$ \\
\hline
\end{tabular}

to $171.3 \mathrm{~V}$ at operation with increased speed. The amplitude of the second harmonic ${ }^{2} v_{\mathrm{q} 1}$ increases proportionally to the phase voltage ${ }^{1} v_{\mathrm{Ph}}$, for constant speed. For the increased speed scenario, the amplitude of the second harmonic increases by $116 \%$, whereas the average voltage $\bar{v}_{\mathrm{q} 1}$ increases only by $50 \%$. The reason for this is the increased impedance of the inter-turn circuit, due to the increased electrical frequency.

\section{B. Fault Current}

The simulation results of the fault current for the different scenarios are shown in Fig. 8. The inter-turn fault causes a fault current which consists primarily of the fundamental component ${ }^{1} i_{\mathrm{F}}$. Table IV summarizes the simulation results of the fault current for the FEA and the analytical model. The minimum deviation of the FEA and analytical model occurs in case of no load operation. The fault current ${ }^{1} i_{\mathrm{F}}$ of the analytical model differs in this case by $0.3 \%$ in comparison to the FEA model. The maximum deviation occurs under increased load operation. In this case, the fundamental components differ by $5.8 \%$. The amplitude of the fault current is the lowest for the no load operation as the phase voltage ${ }^{1} v_{\mathrm{Ph}}$ is also the lowest. In case of operation with increased speed, the amplitude of the fault current increases by $48 \%$ which is similar to the amplification of the phase voltage ${ }^{1} v_{\mathrm{Ph}}$. Therefore, the fault current ${ }^{1} i_{\mathrm{F}}$ increases proportionally to the phase voltage ${ }^{1} v_{\mathrm{Ph}}$.

\section{Torque}

The simulation results of the electromagnetic torque are shown in Fig. 9. The inter-turn fault causes a reduction of the average electromagnetic torque $\bar{T}_{\mathrm{el}}$ and a second harmonic ${ }^{2} T_{\mathrm{el}}$. Table V summarizes the simulation results of the torque for the FEA and the analytical model. There is a very good accordance of the average torque for the no load, nominal load and increased speed scenario. The average torque is negative

TABLE IV

COMPARISON OF THE FAULT CURRENT

\begin{tabular}{lcc}
\hline & FEA & analytic \\
\hline & ${ }^{1} i_{\mathrm{F}}$ & ${ }^{1} i_{\mathrm{F}}$ \\
\hline no load & $118.9 \mathrm{~A}$ & $118.5 \mathrm{~A}$ \\
nominal load & $119.3 \mathrm{~A}$ & $123.4 \mathrm{~A}$ \\
increased load & $122.5 \mathrm{~A}$ & $130.1 \mathrm{~A}$ \\
increased speed & $172.9 \mathrm{~A}$ & $182.8 \mathrm{~A}$ \\
\hline
\end{tabular}




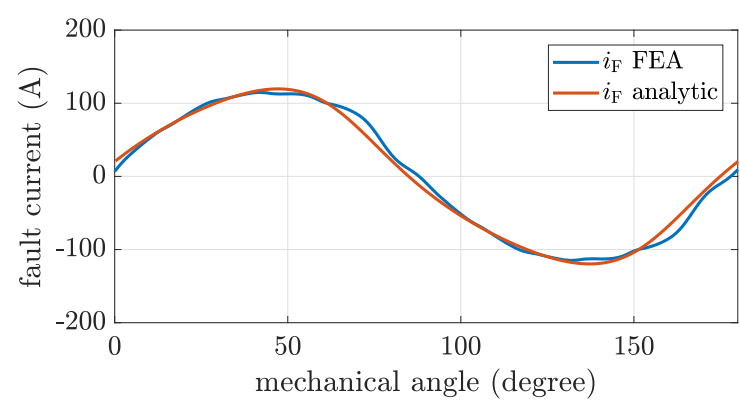

(a) Operation at no load: $\left|i_{\mathrm{dq}}\right|=0 \mathrm{~A}, n=5000 \mathrm{rpm}$

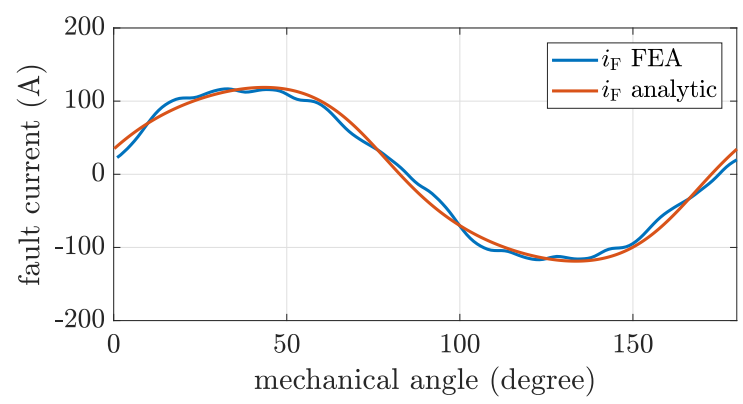

(b) Operation at nominal load: $\left|i_{\mathrm{dq}}\right|=10 \mathrm{~A}, n=5000 \mathrm{rpm}$

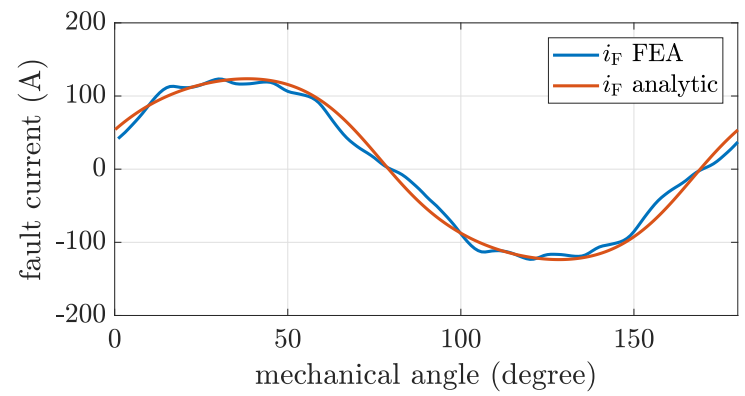

(c) Operation with increased load: $\left|i_{\mathrm{dq}}\right|=14 \mathrm{~A}, n=5000 \mathrm{rpm}$

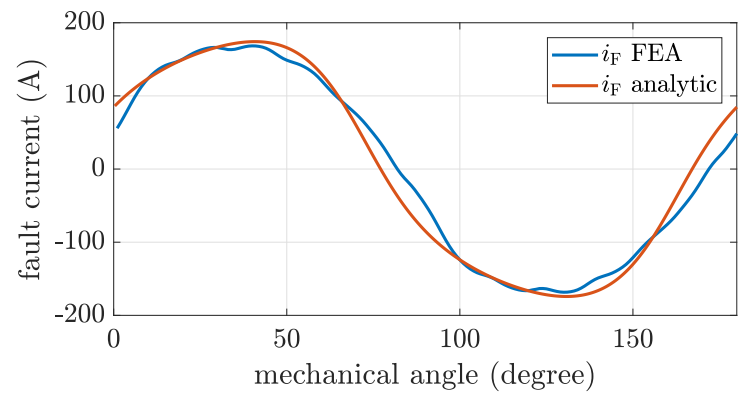

(d) Operation with increased speed: $\left|i_{\mathrm{dq}}\right|=10 \mathrm{~A}, n=7500 \mathrm{rpm}$

Fig. 8. Simulation results of the fault current for the analytical and FEA model with an inter-turn fault in phase $\mathrm{Ph} 1$.

in case of no load operation which means that the machine converts mechanical power into heat. In case of nominal load operation, the average torque $\bar{T}_{\text {el }}$ of the analytical model is reduced by $7.2 \%$, due to the inter-turn fault. There is a deviation of $2.1 \%$ between the average torque of the FEA and analytical model, for the operation with increased load.

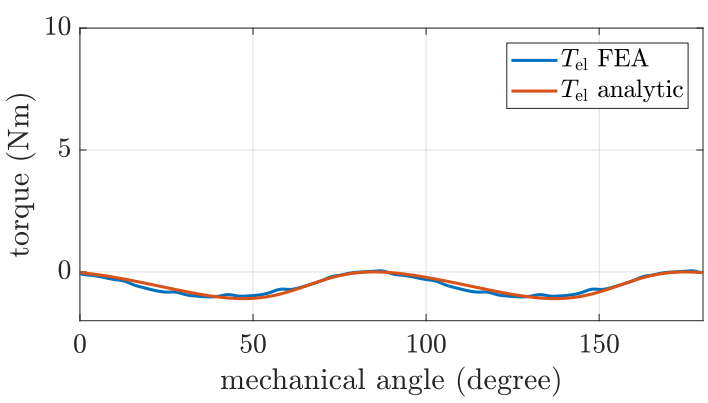

(a) Operation at no load: $\left|i_{\mathrm{dq}}\right|=0 \mathrm{~A}, n=5000 \mathrm{rpm}$

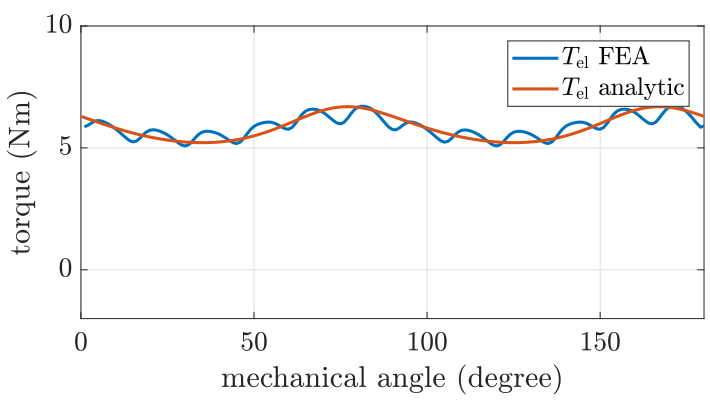

(b) Operation at nominal load: $\left|i_{\mathrm{dq}}\right|=10 \mathrm{~A}, n=5000 \mathrm{rpm}$

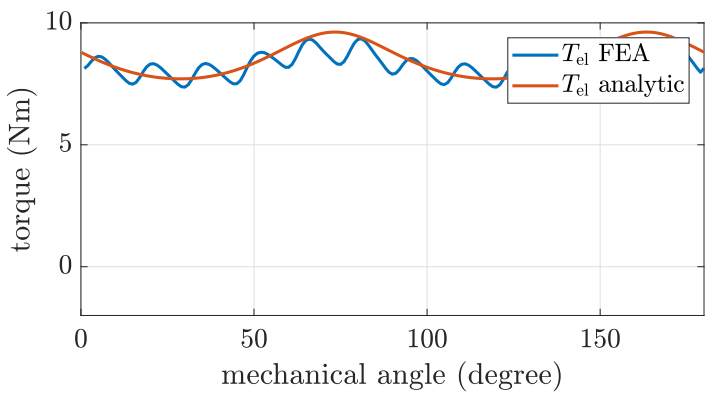

(c) Operation with increased load: $\left|i_{\mathrm{dq}}\right|=14 \mathrm{~A}, n=5000 \mathrm{rpm}$

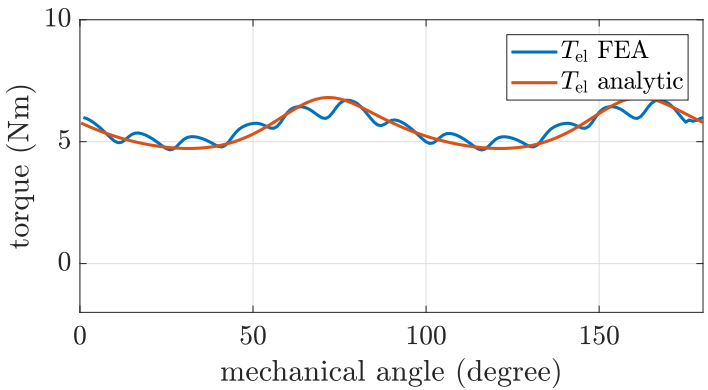

(d) Operation with increased speed: $\left|i_{\mathrm{dq}}\right|=10 \mathrm{~A}, n=7500 \mathrm{rpm}$

Fig. 9. Simulation results of the torque for the analytical and FEA model with an inter-turn fault in phase $\mathrm{Ph} 1$.

The reason for this is the neglected nonlinear magnetic circuit in the analytical model. The minimum deviation of the second harmonic ${ }^{2} T_{\mathrm{el}}$ is $2 \%$ in case of no load operation. The maximum deviation of the second harmonic is in case of increased load operation. The second harmonic ${ }^{2} T_{\mathrm{el}}$ of the FEA model is $40 \%$ smaller, which means that the nonlinear 
TABLE V

COMPARISON OF THE TORQUE

\begin{tabular}{lcccc}
\hline & \multicolumn{2}{c}{ FEA } & \multicolumn{2}{c}{ analytic } \\
\hline & $\bar{T}_{\text {el }}$ & ${ }^{2} T_{\text {el }}$ & $\bar{T}_{\text {el }}$ & ${ }^{2} T_{\text {el }}$ \\
\hline no load & $-0.51 \mathrm{Nm}$ & $0.51 \mathrm{Nm}$ & $-0.50 \mathrm{Nm}$ & $0.50 \mathrm{Nm}$ \\
nominal load & $5.92 \mathrm{Nm}$ & $0.52 \mathrm{Nm}$ & $5.94 \mathrm{Nm}$ & $0.71 \mathrm{Nm}$ \\
increased load & $8.34 \mathrm{Nm}$ & $0.54 \mathrm{Nm}$ & $8.52 \mathrm{Nm}$ & $0.89 \mathrm{Nm}$ \\
increased speed & $5.61 \mathrm{Nm}$ & $0.73 \mathrm{Nm}$ & $5.62 \mathrm{Nm}$ & $0.98 \mathrm{Nm}$ \\
\hline
\end{tabular}

magnetic circuit attenuates the torque ripple. Therefore, the analytical model provides a worst case estimation. In case of operation with the increased speed scenario, the amplitude of the second harmonic ${ }^{2} T_{\mathrm{el}}$ of the analytical model increases by $38 \%$ compared with the nominal load scenario.

\section{CONCLUSION}

With the presented model, we enable the simulation of six-phase PMSMs with stator winding faults on turn level. The acausal implementation allows an initial analysis of the faulty machine behavior without interference of a current controller by using current sources. In this paper, we compare the accuracy of the analytical model with the FEA model. We do not concentrate on the characteristics of different stator winding faults. Therefore, we focus on a detailed analysis of the dq-voltages of the first three-phase system. The analysis of the frequency spectra of the voltages shows that an interturn fault causes second and fourth harmonics in the dqvoltages which mainly depend on the amplitude of the phase voltage. The amplitudes of the harmonics further depend on the speed of the rotor, which affects the induced voltage and the impedance of the short circuit path. The simulation results show that the fundamental component of the fault current is proportional to the phase voltage. The analysis of the fault current is essential to estimate in a next step the developed heat in the stator winding, and thus, the remaining lifetime of the machine. The analysis of the electromagnetic torque shows the stator winding fault effects on the mechanical side of the propulsion system. The average torque decreases for increasing fault currents in order to fulfill the overall power balance. The second harmonic of the torque increases proportionally to the phase voltage, but there is also a strong dependency on the phase currents and therefore also on the magnetic saturation level. There are differences among the analytical and FEA simulation results which depend on the operating scenario. The best accordance is achieved for the no load and nominal load operation, because of the linearity of the magnetic circuit for small currents. The deviation between the two models is primarily due to the nonlinear behavior of the magnetic circuit in the FEA model, which can be seen at the increased load scenario. Although there is a good accordance of the results, the accuracy can be improved, by determining new machine parameters for the operating point of interest. The main advantage of the analytical model is the significantly reduced computation time, which is in average
200 times faster. Furthermore, stator winding faults can be simulated by simply adding short or open circuit paths to the stator winding circuit of Fig. 3 and different machine designs can be analyzed, by adapting the machine parameters of the model. In a next step, we analyze the faulty machine behavior with the interference of a current controlled VSI, which is essential for the development of an FMS in safety critical applications. With the analysis from the pure machine behavior to the machine behavior with complex time-variant control parameters, effective control strategies for fault tolerant operation can be developed. We currently design a test-bench to validate the analytical and the FEA model.

\section{REFERENCES}

[1] A. Mohammadpour, S. Mishra, and L. Parsa, "Fault-tolerant operation of multiphase permanent-magnet machines using iterative learning control," IEEE Journal of Emerging and Selected Topics in Power Electronics, vol. 2, no. 2, pp. 201-211, June 2014.

[2] R. Isermann, Mechatronische Systeme: Grundlagen. 2. Auflage, Springer-Verlag, ISBN 978-3-540-32336-5, 2007.

[3] Y. Lee and T. G. Habetler, "An on-line stator turn fault detection method for interior pm synchronous motor drives," in APEC 07 - Twenty-Second Annual IEEE Applied Power Electronics Conference and Exposition, Feb 2007, pp. 825-831.

[4] G. M. Joksimovic and J. Penman, "The detection of inter-turn short circuits in the stator windings of operating motors," IEEE Transactions on Industrial Electronics, vol. 47, no. 5, pp. 1078-1084, Oct 2000.

[5] M. J. Duran and F. Barrero, "Recent advances in the design, modeling, and control of multiphase machinespart ii," IEEE Transactions on Industrial Electronics, vol. 63, no. 1, pp. 459-468, 2016.

[6] J. Farooq, T. Raminosoa, A. Djerdir, and A. Miraoui, "Modelling and simulation of stator winding interturn faults in permanent magnet synchronous motors," COMPEL -The international journal for computation and mathematics in electrical and electronic engineering, vol. 27, no. 4 , pp. 887-896, 2008.

[7] L. Romeral, J. Urresty, J. Ruiz, and A. Espinosa, "Modeling of surface mounted permanent magnet synchronous motors with stator winding interturn faults," IEEE Transactions on Industrial Electronics, vol. 58, no. 5, pp. 1576-1585, May 2011.

[8] S. Foitzik and M. Doppelbauer, "Simulation of stator winding faults with an analytical model of a pmsm," IEEE Power Electronis, Drives and Energy Systems Conference, 2018.

[9] C. R. da Silva, M. B. R. Correa, C. B. Jacobina, A. M. N. Lima, E. R. C da Silva, R. N. Andriamalala, and H. Razik, "A new approach for interturn short-circuit detection in six-phase induction motor," pp. 49694974, 2006.

[10] E. A. Klingshirn, "High phase order induction motors - part i-description and theoretical considerations," IEEE Transactions on Power Apparatus and Systems, vol. PAS-102, pp. 47-53, 1983.

[11] J. R. Hendershot and T. J. E. Miller, Design of brushless permanentmagnet machines. Motor Design Books, 2010.

[12] M. Kaufhold, H. Aninger, M. Berth, J. Speck, and M. Eberhardt, "Electrical stress and failure mechanism of the winding insulation in pwm-inverter-fed low-voltage induction motors," IEEE Transactions on Industrial Electronics, vol. 47, no. 2, pp. 396-402, 2000.

[13] J. Kofránek, M. Mateják, P. Privitzer, and M. Tribula, "Causal or acausal modeling: labour for humans or labour for machines," Technical Computing Prague, pp. 1-16, 2008.

[14] O. A. Mohammed, S. Liu, and Z. Liu, "Physical modeling of pm synchronous motors for integrated coupling with machine drives," IEEE Transactions on Magnetics, vol. 41, no. 5, pp. 1628-1631, 2005.

[15] L. Quval and H. Ohsaki, "Nonlinear abc-model for electrical machines using n-d lookup tables," IEEE Transactions on Energy Conversion, vol. 30, no. 1, pp. 316-322, March 2015. 